\title{
Relative importance of dynamical and chemical contributions to Arctic wintertime ozone
}

\author{
S. Tegtmeier, ${ }^{1,2}$ M. Rex, ${ }^{1}$ I. Wohltmann, ${ }^{1}$ and K. Krüger $^{3}$ \\ Received 6 April 2008; revised 25 June 2008; accepted 17 July 2008; published 3 September 2008.
}

[1] We present the first complete budget of the interannual variability in Arctic springtime ozone taking into account anthropogenic chemical and natural dynamical processes. For the winters 1991/1992 to 2003/2004 the Arctic chemical ozone loss is available from observations. This work investigates the dynamical supply of ozone to the Arctic polar vortex due to mean transport processes for the same winters. The ozone supply is quantified in a vortexaveraged framework using estimates of diabatic descent over winter. We find that the interannual variability of both dynamical ozone supply and chemical ozone loss contribute, in equal shares, to the variability of the total ozone change. Moreover, together they explain nearly all of the interannual variability of Arctic springtime column ozone. Variability in planetary wave activity, characterized by the Eliassen-Palm flux at $100 \mathrm{hPa}$, contributes significantly to the variability of ozone supply, chemical ozone loss and total springtime ozone. Citation: Tegtmeier, S., M. Rex, I. Wohltmann, and K. Krüger (2008), Relative importance of dynamical and chemical contributions to Arctic wintertime ozone, Geophys. Res. Lett., 35, L17801, doi:10.1029/ 2008GL034250.

\section{Introduction}

[2] Vortex averages of Arctic column ozone exhibit pronounced interannual variability in late winter and spring [World Meteorological Organization (WMO), 2003], which is in contrast to a much smaller degree of interannual variability in autumn [e.g., Rex et al., 2000]. Therefore, the variability of the Arctic ozone layer in spring results from the variability of winter processes. A reliable prediction and identification of the ozone recovery in a future climate is limited by our understanding of these processes [WMO, 2007]. Changes in the abundance of ozone are driven by chemical and dynamical processes, i.e.

$$
\Delta \mathrm{O}_{3, \text { tot }}=\Delta \mathrm{O}_{3, \text { chem }}+\Delta \mathrm{O}_{3, \text { trans }}
$$

where $\Delta \mathrm{O}_{3, \text { tot }}$ denotes the fall to spring change in mean total ozone inside the Arctic polar vortex. $\Delta \mathrm{O}_{3, \text { chem }}$ denotes the chemical loss of total ozone, i.e. the difference in observed spring total ozone and total ozone that would have been present in spring in the absence of chemical loss, all

\footnotetext{
${ }^{1}$ Alfred Wegener Institute for Polar and Marine Research, Potsdam, Germany.

${ }^{2}$ Now at Environment Canada, Toronto, Ontario, Canada.

${ }^{3}$ IFM-GEOMAR, Kiel, Germany.
}

Copyright 2008 by the American Geophysical Union. 0094-8276/08/2008GL034250 else being equal [Rex et al., 2002]. $\Delta \mathrm{O}_{3, \text { trans }}$ denotes the change in total ozone that results from transport processes.

[3] Past research has focussed mainly on chemical ozone destruction. Several approaches to estimate the chemical loss term and its interannual variability have been developed [Harris et al., 2002, and references therein]. As a consequence, estimates of $\Delta \mathrm{O}_{3 \text {,chem }}$ are available for the winters 1991/1992 to the present [e.g., Rex et al., 2002; $W M O, 2007$ ] with uncertainties around 20\% [Harris et al., 2002].

[4] Chemistry explains just one component of the interannual variability of Arctic ozone. The other component results from the variability of dynamically driven transport processes and consists of: (a) the transport of ozone due to meridional mixing across the vortex edge, and (b) the transport of ozone due to mean transport by the residual circulation (i.e. the transport of ozone by advection in contrast to the transport by two-way mixing). Mixing is not related to net mass flux but it can contribute to the flux of ozone due to the meridional gradient in ozone mixing ratios. The degree of isolation of the polar vortex from air in midlatitudes and therefore the relative importance of irreversible meridional transport across the vortex edge varies from year to year. Generally the polar vortex is considered to be relatively isolated with a steep gradient in potential vorticity at the edge of the polar vortex constituting an effective barrier to mixing [WMO, 2003, section 3.2.1.3, and references therein].

[5] The supply of ozone to the polar vortex due to mean transport is driven by the residual circulation. The theoretical basis of the residual circulation has been laid out by the Transformed Eulerian Mean theory [e.g., Andrews and McIntyre, 1976; Holton et al., 1995]. The transport of ozone by the residual circulation has been determined to be an important contributor to the interannual variability of ozone at all latitudes [e.g., Fusco and Salby, 1999; Randel et al., 2002]. However, so far the transport of ozone to the polar vortex has not been quantitatively estimated.

[6] The polar branch of the residual circulation results in diabatic descent within the polar vortex. By using diabatic heating rates from radiative transfer calculations, estimates of the diabatic descent have been derived for selected winters [e.g., Manney et al., 1994; Rosenfield and Schoeberl, 2001] or in the form of a multi-year time series (19572004) [Tegtmeier et al., 2008] (hereinafter referred to as T08).

[7] In this study the vortex-averaged diabatic descent from T08 is used to estimate the dynamical supply of ozone produced by mean transport. The ozone supply is quantified for recent winters, where estimates of the chemical loss term are available. We calculate the fraction of interannual Arctic ozone variability caused by dynamical transport, and that 

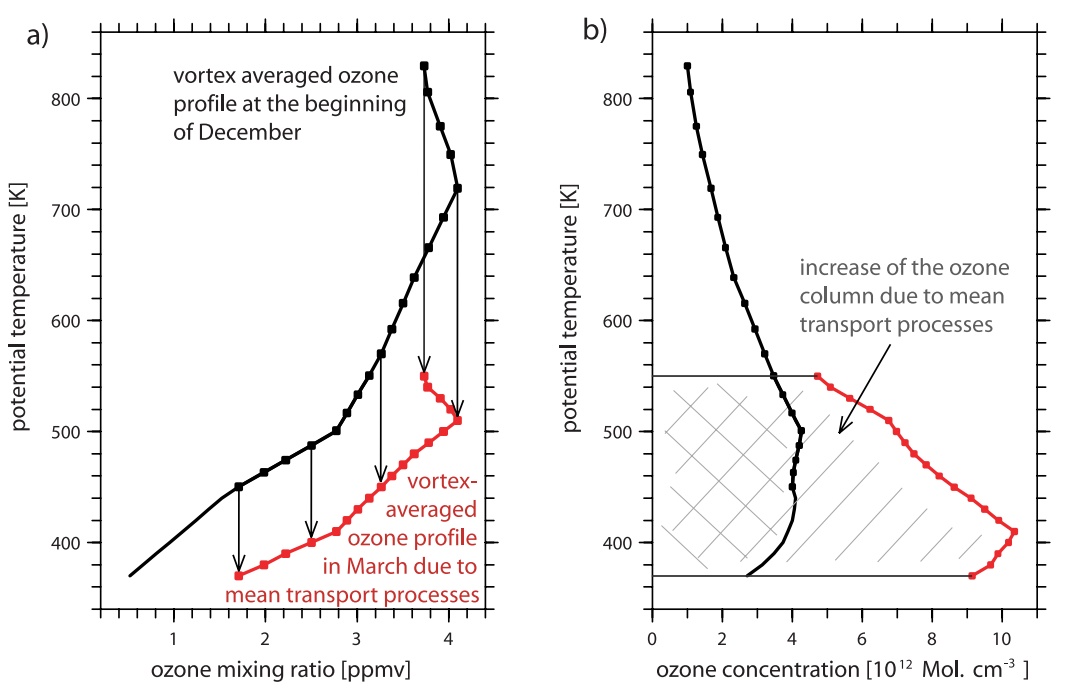

Figure 1. Profiles of (a) ozone mixing ratio and (b) ozone concentration at the beginning of the winter 2000/2001 based on observations (black) and at the end of the winter 2000/2001 resulting from our model calculations (red). The vortexaveraged diabatic descent for the winter 2000/2001 is shown by vertical arrows for five levels.

caused by chemical ozone depletion. The relationships between Eliassen-Palm (EP)-flux and change in total ozone during winter, dynamical supply of ozone, and chemical loss of ozone are investigated.

\section{Method}

[8] The stratospheric residual circulation transports ozone rich air from lower latitudes into the polar vortex. At the same time, air masses below $400 \mathrm{~K}$ with low ozone mixing ratios are transported equatorwards. These processes produce a net dynamical supply of ozone to the polar vortex. The meridional transport leads to adiabatic compression and heating in the polar vortex, which then induces vertical transport. In the isentropic coordinate system, this vertical transport is described by diabatic descent rates. We use the T08 time series of the total winter diabatic descent to quantify the increase of total ozone due to these transport processes in a vortex-averaged framework.

[9] The vortex-averaged descent estimation is based on reverse domain filling trajectory calculations coupled with diabatic heating rate calculations carried out in the polar stratosphere of the $\mathrm{NH}$ winters. Input data for temperature and horizontal wind fields are obtained from the European Centre for Medium-Range Weather Forecasts (ECMWF) reanalysis (ERA40) [Uppala et al., 2005] and after 1999 from the ECMWF operational analysis [Simmons et al., 2005]. For December 1995 and 1996 an unrealistic vertical oscillatory temperature structure is found in the Arctic stratosphere in ERA40 [Uppala et al., 2005]. These oscillations might influence the calculated diabatic descent. Therefore these two winters are distinguished from the other winters in the presentation of results to follow.

[10] A vortex-averaged ozone mixing ratio profile for the beginning of each winter is calculated from the ozone dataset CATO [Brunner et al., 2006] as an average of mid November to mid December ozone profiles. CATO provides a homogeneous data set for the years of interest and doesn't suffer from the limited availability of sonde data in the polar vortex in early winter. The edge of the vortex is defined based on the criterion of Nash et al. [1996] using the Rossby-Ertel potential vorticity. Figure 1a shows, as an example, the vortex-averaged ozone profile at the beginning of the winter 2000/2001. During the winter the air masses experience diabatic descent. If there would be no chemical ozone loss and no meridional mixing the descending air masses would maintain their corresponding values of ozone mixing ratio. To separate the influence of mean transport from the effects of chemical loss and meridional mixing, we treat the ozone mixing ratio as a conserved quantity. We use the T08 vortex-averaged diabatic descent from beginning of December to mid March to assign each air mass (with its corresponding fixed ozone mixing ratio) to the potential temperature which it would possess near the end of the vortex descent in mid March. The diabatic descent is given for 19 vertical levels between $\Theta_{e}=370$ and $550 \mathrm{~K}$. $\Theta_{e}$ is defined as the potential temperature an air mass reaches in spring [Rex et al., 2006]. The new vortex-averaged ozone profile estimated with our method is therefore given by 19 data points between $\Theta_{e}=370$ and $550 \mathrm{~K}$. Figure 1a shows example vortex-averaged descent for five levels for the winter 2000/2001, connecting the initial (December, black line) and resulting (mid March, red line) ozone profile.

[11] In order to estimate the influence of the diabatic descent on the total ozone column the corresponding ozone concentration profiles at the beginning and end of the winter are calculated (Figure 1b). The profile estimated for the end of the winter would match the real vortex-averaged ozone profile if there were no chemical ozone loss and no meridional mixing but only mean transport processes. The influence of the mean transport is apparent in the larger values of ozone concentration at the end of the winter.

[12] Based on the two ozone concentration profiles, the partial ozone column between $\Theta_{e}=370$ and $550 \mathrm{~K}$ at the beginning of winter (marked area bounded by the black curve in Figure 1b) and at the end of winter (entire marked area bounded by the red curve in Figure 1b) are calculated. The difference between the two partial ozone columns equals the dynamical ozone supply by mean transport 


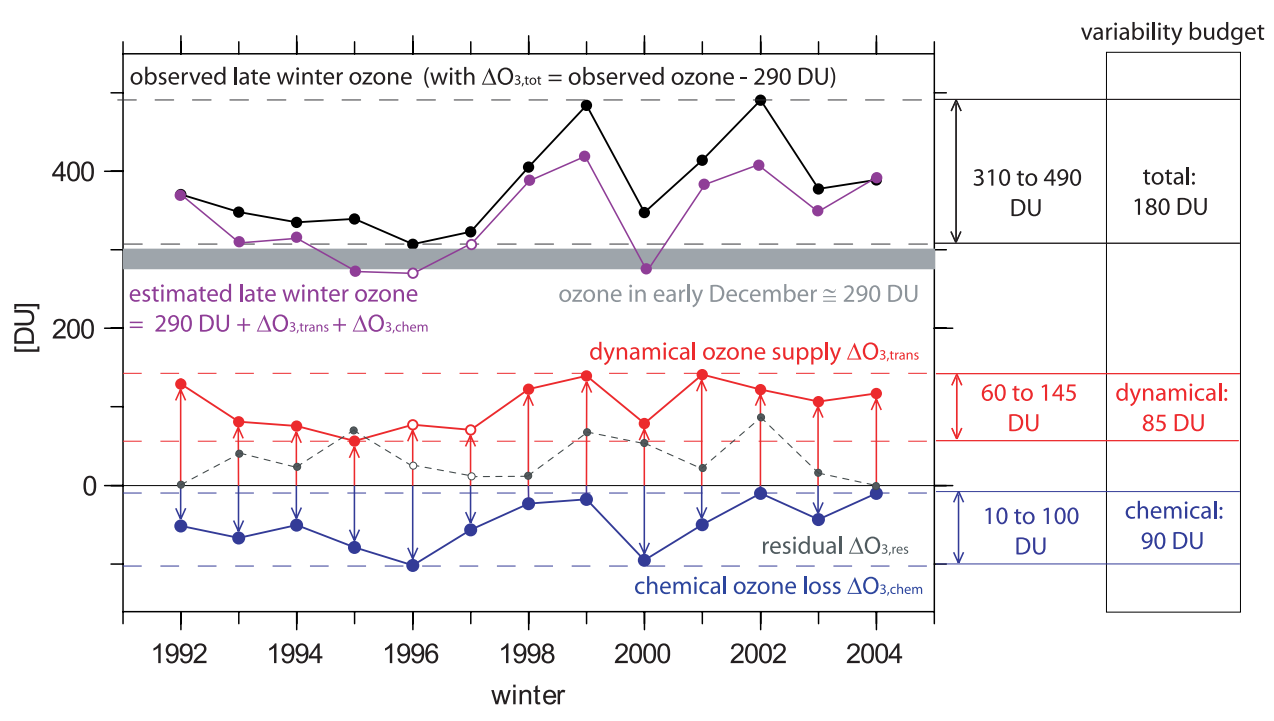

Figure 2. Interannual variability of the observed late winter ozone column (black), the dynamical supply of ozone to the polar vortex (red) and the chemical loss of ozone over the winter (blue) for the winters 1991/1992 to 2003/2004. The range of variability for the three quantities is given on the right hand side. Estimated late winter ozone column (violet) and residual between observed and estimated late winter ozone (dashed grey) are shown for the same years. Results for the winters 1995/1996 and 1996/1997 are marked by open circles.

processes within the region between $\Theta_{e}=370$ and $550 \mathrm{~K}$. We do not take into account the net ozone supply above $\Theta_{e}=550$ which we consider to be small since ozone profiles at the beginning and end of winter converge quickly above $550 \mathrm{~K}$. Furthermore, we do not take into account the ozone supply below $\Theta_{e}=370 \mathrm{~K}$. Since the polar vortex below $370 \mathrm{~K}$ is very unstable, it is not possible to estimate the vortex-averaged descent. However, diabatic descent rates below $370 \mathrm{~K}$ are quite small [e.g., Greenblatt et al., 2002] and the main influence of the diabatic descent on total ozone is seen between $\Theta_{e}=370$ and $550 \mathrm{~K}$.

[13] Based on this approach we calculate the dynamical ozone supply to the polar vortex between $\Theta_{e}=370$ and $550 \mathrm{~K}$ caused by mean transport for the winters 1991/1992 to $2003 / 2004$ not taking into account any meridional mixing. For simplicity we will refer to this dynamical ozone supply term as the change in total ozone that results from transport processes $\Delta \mathrm{O}_{3 \text {,trans. }}$.

\section{Interannual Variability of Dynamical and Chemical Contributions}

[14] The calculated time series of the dynamical ozone supply $\Delta \mathrm{O}_{3, \text { trans }}$ for the winters $1991 / 1992$ to $2003 / 2004$ is displayed as red line in Figure 2. The blue and the black line of Figure 2 show the chemical loss of ozone over the winter [Rex et al., 2006] and the observed late winter ozone inside the polar vortex, respectively. All three quantities have been estimated based on the same vortex definition. The time series of observed total ozone is derived from the data set of the NH ozonesonde station network used by Rex et al. [2006], applying the same method to estimate the vortex-average. While the procedures used to estimate the dynamical ozone supply and the chemical ozone loss have been applied to slightly different time periods, the quantities produced are valid estimates of the respective terms from
December to March. The violet line in Figure 2 shows the late winter ozone estimated as the sum of the chemical ozone loss, the dynamical ozone supply and an approximation of the December total ozone column: 290 DU. The chemical loss and the dynamical supply show a very similar year-to-year variability and together explain a large fraction of the observed fall to spring change in total ozone. The residual change in total ozone $\Delta \mathrm{O}_{3 \text {,res }}$ may be attributed to transport of ozone due to meridional mixing and dynamical supply above or below the $\Theta_{e}=370$ to $550 \mathrm{~K}$ region. The residual term $\Delta \mathrm{O}_{3 \text {,res }}$ can be estimated as

$$
\Delta \mathrm{O}_{3, \text { res }}=\Delta \mathrm{O}_{3, \text { tot }}-\left(\Delta \mathrm{O}_{3, \text { chem }}+\Delta \mathrm{O}_{3, \text { trans }}\right),
$$

and is influenced by the errors of the dynamical supply and the chemical loss. $\Delta \mathrm{O}_{3 \text {,res }}$ is displayed as dashed grey line in Figure 2 and shows a mean of $38 \mathrm{DU}$ and a standard deviation $\sigma_{\text {res }}$ of $29 \mathrm{DU}$. The values of $\Delta \mathrm{O}_{3 \text {,res }}$ are mainly positive, due to not taking into account the processes below $\Theta_{e}=370 \mathrm{~K}$.

[15] The chemical ozone loss varies between -10 and -100 DU with a mean of -50 DU and a standard deviation $\sigma_{\text {chem }}$ of 29 DU. The dynamical ozone supply is characterized by positive values between 60 and 145 DU with a mean of $101 \mathrm{DU}$ and a standard deviation $\sigma_{\text {trans }}$ of $28 \mathrm{DU}$. Both time series show nearly the same standard deviation and therefore the variability of late winter ozone is influenced in equal shares by the variability of dynamical supply and chemical loss. Winters with a maximum dynamical ozone supply (e.g., 1998/1999) show nearly no chemical ozone loss, whereas winters with little dynamical ozone supply (e.g., 1999/2000) are characterized by strong chemical ozone destruction. This reflects the fact that the dynamical supply and the chemical loss are both strongly correlated with dynamically driven temperature anomalies 

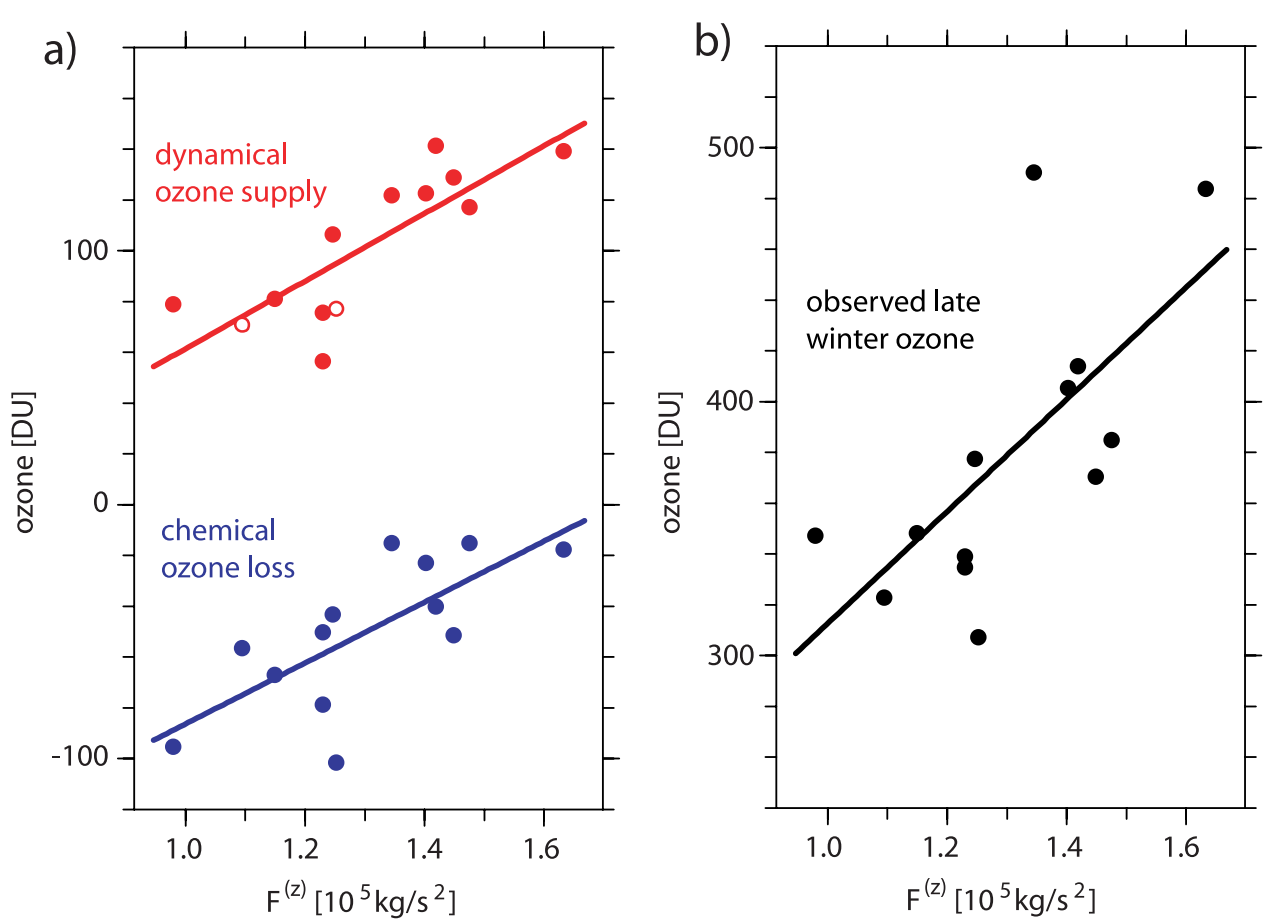

Figure 3. Correlation between the EP-flux and (a) the dynamical supply of ozone (red) and the chemical loss of ozone (blue) and (b) the observed late winter ozone (black). Results for the dynamical supply of ozone for 1995/1996 and 1996/ 1997 are marked by open circles.

in the polar vortex. The connection between dynamical supply and chemical loss is confirmed by the high correlation coefficient of 0.7 between the two time series. Coefficients greater than 0.55 are statistically significant at the $95 \%$ confidence level.

[16] The observed total change in ozone during winter varies between 10 and 190 DU with a standard deviation $\sigma_{\text {tot }}$ of $55 \mathrm{DU}$. The interannual variability of the fall to spring change in ozone can be explained by the variability of the component time series, and the interaction between them:

$$
\sigma_{\text {tot }}^{2}=\sigma_{\text {trans }}^{2}+\sigma_{\text {chem }}^{2}+2 \cdot \operatorname{cov}_{\text {trans,chem }}+\text { res }
$$

with res $=\sigma_{\text {res }}^{2}+2 \cdot\left(\operatorname{cov}_{\text {trans,res }}+\operatorname{cov}_{\text {chem,res }}\right)$, where $\operatorname{cov}_{\mathrm{x}, \mathrm{y}}$ denotes the covariance between the time series $\mathrm{x}$ and $\mathrm{y}$. We find no connection between $\Delta \mathrm{O}_{3 \text {,res }}$ and either $\Delta \mathrm{O}_{3 \text {,trans }}$ or $\Delta \mathrm{O}_{3 \text {,chem }}$, reflected by low correlation coefficients of -0.15 and -0.19 , respectively. Therefore, the term res is relatively small and represents only a small fraction of the total variance of the fall to spring change in ozone $\sigma_{\text {tot. }}^{2}$ The main part of the variance $\sigma_{\text {tot }}^{2}$ results from the term $\sigma_{\text {trans }}^{2}+$ $\sigma_{\text {chem }}^{2}+2 \cdot \operatorname{cov}_{\text {trans,chem. }}$. Consequently, a large fraction of the variability of the fall to spring change in ozone is explained by the variability of the dynamical ozone supply, the variability of the chemical ozone loss and the connection between these two time series.

\section{Correlations With EP-Flux}

[17] The residual circulation is driven by planetary waves which can be characterized by the EP-flux entering the stratosphere. Atmospheric wave activity causes stratospheric temperature anomalies as illustrated by the strong correlation between polar temperatures and the vertical component of the EP-flux [Newman et al., 2001]. Deviations of the temperature from radiative equilibrium cause diabatic descent, as reflected by a strong correlation between diabatic descent and both temperature and EP-flux (T07). Therefore we expect to find a close connection between the strength of wave activity and the dynamical ozone supply. Additionally, the polar temperature has a strong influence on ozone chemistry and we also expect to find a close connection between wave activity and chemical ozone loss. Since dynamical supply of ozone and chemical loss of ozone are both strongly influenced by the EP-flux and together explain most of the variability of the fall to spring change in ozone, there must exist a strong correlation between EP-flux and total springtime Arctic ozone, as first shown by Randel et al. [2002]. We will focus on demonstrating the connections between EPflux and the three time series: $\Delta \mathrm{O}_{3 \text {,trans }}, \Delta \mathrm{O}_{3 \text {,chem }}$ and total ozone in spring.

[18] The EP-flux is taken at $100 \mathrm{hPa}$, averaged from December to February over $45^{\circ} \mathrm{N}$ to $75^{\circ} \mathrm{N}$. The data are obtained from ERA40 and after 1999 from the ECMWF operational analysis. The upper portion of Figure 3a shows a scatter plot of the dynamical ozone supply and the vertical component of the EP-flux, $F^{(z)}$. The plot illustrates the correlation between $\Delta \mathrm{O}_{3 \text {,trans }}$ and EP-flux, as expected. For strong wave activity, high values of dynamical ozone supply are found, whereas low values of $F^{(z)}$ are associated with weak ozone supply. The high correlation coefficient of 0.81 confirms the influence of atmospheric wave activity on the dynamical ozone supply. The lower portion of Figure 3a 
displays a similar scatter plot for the chemical loss of ozone and EP-flux. For a stronger wave activity with higher values of $F^{(z)}$ we find less chemical ozone destruction, whereas small values of $F^{(z)}$ lead to strong ozone destruction in a cold and stable polar vortex. The correlation coefficient here $(\mathrm{r}=0.73)$ is slightly less strong than the correlation coefficient between $\Delta \mathrm{O}_{3 \text {,trans }}$ and EP-flux.

[19] Finally we examine the connection between EP-flux and the total ozone column in late winter (Figure 3b). As expected we find a clear correlation $(\mathrm{r}=0.68)$ where high values of $F^{(z)}$ are associated with high values of total ozone in spring. The correlation coefficient is smaller than correlation coefficients between $F^{(z)}$ and the dynamical supply or the chemical loss. Since the amount of total ozone in spring is influenced by the residual term, which is not correlated with $F^{(z)}$, we expect a lower correlation coefficient for the total ozone column.

\section{Conclusions}

[20] The influence of mean transport processes by the residual circulation on the total ozone column in spring is quantified. The net dynamical supply of ozone caused by these transport processes is estimated based on vortexaveraged diabatic descent for the winters 1991/1992 to 2003/2004. Together with the chemical loss term, which is available for the same winters, the estimated dynamical ozone supply explains a large fraction of the observed fall to spring change in ozone. The dynamical ozone supply and the chemical ozone loss influence in equal shares the interannual variability of total ozone in late winter. Additionally, nearly all of the interannual variability of the fall to spring change in ozone is explained by the variability of the dynamical supply, the variability of the chemical loss and the connection between these two time series.

[21] Variability in planetary wave activity, characterized by the EP-flux entering the stratosphere, contributes significantly to the variability of both the net transport of ozone through the residual circulation and the chemical ozone loss during winter, and therefore to the variability of total ozone at the end of winter. This is confirmed by high correlation coefficients between the four time series.

[22] The calculated time series of the dynamical ozone supply can provide a useful diagnostic to validate the influence of transport on total ozone in spring in coupled Chemistry-Climate Models. Continuing the time series for the most recent $\mathrm{NH}$ winters and for $\mathrm{SH}$ winters can be investigated in a future study.

[23] Acknowledgments. We thank D. Brunner for providing the ozone data-set CATO and the ECMWF for providing their operational and reanalysis data. The work has been supported by the EC under contract 505390-GOCE-CT-2004 (SCOUT-O3).

\section{References}

Andrews, D. G., and M. E. McIntyre (1976), Planetary waves in horizontal and vertical shear: The generalised Eliassen-Palm relation and the mean zonal acceleration, J. Atmos. Sci., 33, 2031.

Brunner, D., J. Staehelin, H.-R. Künsch, and G. E. Bodeker (2006), A Kalman filter reconstruction of the vertical ozone distribution in an equivalent latitude-potential temperature framework from TOMS/ GOME/SBUV total ozone observations, J. Geophys. Res., 111, D12308, doi:10.1029/2005JD006279.

Fusco, A. C., and M. L. Salby (1999), Interannual variations of total ozone and their relationship to variations of planetary wave activity, J. Clim., $12,1619$.

Greenblatt, J. B., et al. (2002), Tracer-based determination of vortex descent in the 1999/2000 Arctic winter, J. Geophys. Res., 107(D20), 8279, doi:10.1029/2001JD000937.

Harris, N. R. P., M. Rex, F. Goutail, B. M. Knudsen, G. L. Manney, R. Müller, and P. von der Gathen (2002), Comparison of empirically derived ozone losses in the Arctic vortex, J. Geophys. Res., 107(D20), 8264, doi:10.1029/2001JD000482.

Holton, J. R., P. H. Haynes, M. E. McIntyre, A. R. Douglass, R. B. Rood, and L. Pfister (1995), Stratosphere-troposphere exchange, Rev. Geophys, 33, 403.

Manney, G. L., R. W. Zurek, A. O’Neill, and R. Swinbank (1994), On the motion of air through the stratospheric polar vortex, J. Atmos. Sci., 51, 2973.

Nash, E. R., P. A. Newman, J. E. Rosenfield, and M. R. Schoeberl (1996), An objective determination of the polar vortex using Ertel's potential vorticity, J. Geophys. Res., 101, 9471.

Newman, P., E. Nash, and J. Rosenfield (2001), What controls the temperature of the Arctic stratosphere during the spring?, J. Geophys. Res., $106,19,999$.

Randel, W., F. Wu, and R. Stolarski (2002), Changes in column ozone correlated with the stratospheric EP flux, J. Meteorol. Soc. Jpn., 80, 849.

Rex, M., et al. (2000), Arctic and Antarctic ozone layer observations: Chemical and dynamical aspects of variability and long-term changes in the polar stratosphere, Polar Res., 19, 193.

Rex, M., et al. (2002), Chemical depletion of Arctic ozone in winter 1999/ 2000, J. Geophys. Res., 107(D20), 8276, doi:10.1029/2001JD000533.

Rex, M., et al. (2006), Arctic winter 2005: Implications for stratospheric ozone loss and climate change, Geophys. Res. Lett., 33, L23808, doi:10.1029/2006GL026731.

Rosenfield, J. E., and M. R. Schoeberl (2001), On the origin of polar vortex air, J. Geophys. Res., 106, 33,485.

Simmons, A., et al. (2005), ECMWF analyses and forecasts of stratospheric winter polar vortex breakup: September 2002 in the Southern Hemisphere and related events, J. Atmos. Sci., 62, 668.

Tegtmeier, S., K. Krüger, I. Wohltmann, K. Schoellhammer, and M. Rex (2008), Variations of the residual circulation in the Northern Hemispheric winter, J. Geophys. Res., doi:10.1029/2007JD009518, in press.

Uppala, S., et al. (2005), The ERA-40 re-analysis, Q. J. R. Meteorol. Soc., 131, 2961.

World Meteorological Organization (WMO) (2003), Scientific assessment of ozone depletion 2002, Rep. 47, Global Ozone Res. Monit. Proj., Geneva, Switzerland.

World Meteorological Organization (WMO) (2007), Scientific assessment of ozone depletion 2006, Rep. 50, Global Ozone Res. Monit. Proj., Geneva, Switzerland.

K. Krüger, IFM-GEOMAR, Düsternbrooker Weg 20, D-24105 Kiel, Germany.

M. Rex and I. Wohltmann, Alfred Wegener Institute for Polar and Marine Research, Telegrafenberg A43, D-14473 Potsdam, Germany.

S. Tegtmeier, Environment Canada, 4905 Dufferin Street, Toronto, ON M3H 5T4, Canada. (susann@atmosp.physics.utoronto.ca) 